\title{
Precursor Models and Early Years Science Learning: A Case Study Related to the Water State Changes
}

\author{
Maria Kambouri-Danos ${ }^{1} \cdot$ Konstantinos Ravanis $^{2} \cdot$ Alain Jameau $^{3} \cdot$ Jean-Marie Boilevin ${ }^{3}$
}

Published online: 18 March 2019

(c) The Author(s) 2019

\begin{abstract}
Children's everyday activities enable them to learn some science even before entering preschool education and children bring these ideas with them when entering education settings. Some of these ideas, or else mental representations, may not be compatible with what is generally accepted by the scientific community. This paper presents the results of an empirical study, focusing on the construction of a precursor model that can support children's scientific learning, in relation to the phenomenon of change of the state of water. The research included 91 children aged 5-6 which participated in a specifically designed teaching intervention. The intervention lasted approximately $55 \mathrm{~min}$ and was conducted at eight stages, during which children's predictions and explanations for simple cases of change of the state of water were recorded. The analysis of children's responses suggests that the specific teaching intervention can have a positive effect on children's thinking in relation to the change of the state of water. A considerable number of pre-schoolers were able to take advantage of their involvement in the teaching intervention and construct a stable precursor model to support the development of their understanding, in relation to the water change of state phenomenon. It appears that precursor models can function in the minds of young children as intermediaries between mental representations of reality and scientific knowledge and prepare children's thinking, forming the basis for a cognitive path towards cognitive processing and the formation of more complex models. The proposed intervention is compatible with the model used in science education and it is proposed to be used in moderation and should not replace children's learning through play.
\end{abstract}

Keywords Precursor model $\cdot$ Preschool age $\cdot$ Water cycle $\cdot$ Early years $\cdot$ Science $\cdot$ Misconceptions

Maria Kambouri-Danos

m.danos@ reading.ac.uk

Konstantinos Ravanis

ravanis@upatras.gr

Alain Jameau

alain.jameau@espe-bretagne.fr

Jean-Marie Boilevin

jean-marie.boilevin@espe-bretagne.fr

1 Institute of Education, University of Reading, Reading, UK

2 Department of Educational Sciences and Early Childhood Education, University of Patras, Patras, Greece

3 Centre de Recherche sur l'Éducation, les Apprentissages et la Didactique (CREAD), ESPE, Université de Bretagne Occidentale, Brest, France

\section{Introduction}

Young children's initiation in science in the early years has been an area of research interest for over 30 years, not only in the context of cognitive, developmental and educational psychology, but also in the context of early childhood education as well as science education (Allen and KambouriDanos 2016; Fleer 1996). In all these contexts, it is apparent that children have the potential to approach phenomena and concepts, to develop reasoning and to construct stable forms and schemas of approaching the natural world (Kampeza 2006; Küçüközer and Bostan 2010; Kambouri 2011; Allen and Kambouri-Danos 2016; Ampartzaki and Kalogiannakis 2016; Pantidos et al. 2017). Based on these approaches, children in everyday life form mental representations in their thoughts about phenomena and concepts studied within science.

Children's learning of science begins long before entering formal education, and much of young children's scientific 
learning comes from the varied environment in and around their homes. Science is part of the children's lives through television science programmes, visits to science museums as well as play time, since children use scientific principles while they play (Bradley 1996). Different reports have highlighted the significant role of play, since it is the key feature of learning in early years education (Sylva et al. 2004; Samuelsson and Carlsson 2006, 2008). Thus, it is thought that children's play is also a key vehicle of promoting science and learning in early years education. Nevertheless, children's mental representations can sometimes be incompatible with the theories, models and laws of physics (i.e. misconceptions). Misconceptions can often pose strong barriers to learning science and can be detrimental to learning (Clement et al. 1989; Kambouri 2015).

In this study, the focus in on how early years teachers can support children's learning of science and how to help children construct their knowledge. To do that, a specific teaching intervention is proposed and evaluated in order to explore the potential impact on children's learning. The intervention suggested in this paper is not being proposed to replace other forms of learning science, such as learning through play, since the authors acknowledge the significance of play in the early years. The main aim of the proposed intervention is to support the children in developing the learning that they already acquire through play and through other forms of learning.

\section{Theoretical Framework}

Constructivism and social constructivism are seen as the basic theories that help us understand how children learn science in the early years and are used to provide the theoretical framework for this paper. Constructivism suggests that children construct their knowledge based on what they already know, while social constructivism emphasises the role of the teacher, giving much more room for an active, involved teacher (Chen 2007). In this sense, the children's own preconstructed concepts determine what more they can learn and how they perceive different phenomena and the world around them (Kambouri 2015).

This paper considers that children's learning of science depends on their ability to process information and this is both a function of what they already know and of their own thinking skills. Their development of thinking and, thus their learning, may be linked with brain maturity as well as cognitive development, and this maturation could be compatible with various development perspectives (De Vries 2000). Children construct their own logical concepts and since concepts do not exist 'out there', concepts cannot be discovered simply by being exposed. Within this framework, it is proposed that some of the activities performed in preschools will have to be devoted to the systematic exploration of science and scientific phenomena (Kampeza and Ravanis 2009).

As mentioned above, occasionally young children's mental representations are sometimes incompatible with the theories, models and laws of physics as these are accepted by the scientific community. This issue has been systematically addressed by research related to science education, where mental representations have formed the basis for the development of teaching interventions that aimed to guide learners' thinking in such way that would encourage the development of cognitive models (accepted by the scientific community). These models allow children to make appropriate descriptions of the physical phenomena they discuss, to give reasoned and rational explanations and to make predictions about the evolution of the physical phenomena, using all the functions of the models presented in the scientific thinking process.

The prospect of developing such models, that can be part of children's thinking processes, is quite different for the particular theoretical stream of early childhood science education. In this theoretical stream, young children's (aged 5-7 years old) limited experiences, developing logical-mathematical thinking and intuitive forms of reflection may not allow, or for the least pose an obstacle, to the construction of integrated mental scientific models. However, children of this age are able to construct precursor entities and use them as part of their thinking, allowing them to do specific things, such as choose the appropriate elements of a natural phenomenon when making descriptions or predictions. 'These precursors are cognitive constructions... generated by the educational context. They constitute the moulds for subsequent cognitive constructions, which without their help, would be difficult, or impossible' (Weil-Barais 2001, p. 188). In recent years, the concept of the precursor model seems to successfully give shape to the issues that arise regarding the approaches that exploit the study of social-didactic interactions for building concepts and phenomena of natural sciences into the thinking of you children. Therefore, 'the precursor models are cognitive entities which: (a) interpose themselves between the original children's representations and the scientific models used in education, and (b) allow pupils to put forth thought processes which, on the one hand, surmount the obstacles of their thinking and, on the other, are compatible with scientific ones' (Ravanis 2017, p. 285).

The concept of the precursor model links with that of cognitive constructivism and social constructivism, as the focus is on the individual learner's understanding. In this paper, the focus is on children's personal constructions of meaning which are developed based on their experiences and interactions. From this point of view, classroom learning should include practical, well-designed activities that 
challenge children's prior learning and misconceptions (Kambouri 2015). In addition, social constructivism highlights how meanings and understandings grow out of social encounters. From this point of view, construction of knowledge is successful when children are exposed to scientific phenomena, take part in scientific activities and are involved in scientific discourses (Driver et al. 2001). In the pre-school context, this suggests that children should be involved in group activities that will enable scientific practices. The concept of the precursor model can offer a framework within which early years teachers can potentially support children construct their knowledge.

\section{Literature Review}

Researching the teaching processes that lead to the formation of precursor models has drawn a lot of research attention in early childhood studies over the last 10 years, as it allows the exploration of both the potential outcome that children's thoughts can reach as well as the phases and the steps undergone during this process. For example, a series of studies on different phenomena and scientific concepts, such as sinking and floating (Canedo-Ibarra et al. 2010), inheritance (Ergazaki et al. 2015), metals (Ravanis et al. 2013) and shadows (Delserieys et al. 2018), find that children aged between 5 and 7 years old are able to move from the original mental representations to precursor models that are compatible with the scientifically accepted knowledge on which formal education is based. In one of these studies, the thermal phenomenon of expansion and contraction of metals is examined through a methodological approach that leads to a continuous exposure to successive experiences of the phenomenon under investigation (Ravanis et al. 2013).

Most studies with young children, looking into the changes in state of matter, focused on children's understanding of the water cycle as a natural phenomenon. There is limited empirical research exploring the changes in state of matter issue as a heat transfer concept and phenomena, while also focusing on children age between 3 and 8 years old. For example, Russell et al. (1989) and Bar (1989) developed a number of activities related to evaporation and the water cycle and used these in order to categorise children's mental representations (the children were aged between 5 and 11 years old). Levins (1992) and Bar and Galili (1994), in two related research projects, attempted to study children's conceptual change in relation to evaporation, but the studies focus on children aged between 3 and 14 years old. Similarly, Ravanis and Bagakis (1998), after exploring children's misconceptions (aged between 5 and 6 years old) applied a special teaching strategy and tried to lead children's thoughts to understand the stages of an evaporation process. Tytler (2000) studied the evolution of mental representations for evaporation and condensation, working with children aged between 6 and 7 years old. Similarly, Cruz-Guzmán et al. (2017), worked with children aged between 2 and 4 years old, studying children's mental representation through a process of predictions and experiments aiming to confirm the state changes of simple daily materials. More recently, a study recorded the mental representations of children aged between 5 and 6 years old, in relation to melting and solidification of a substance that is always found in solid state in daily life (Ravanis 2014).

From this limited number of studies, it seems that children, in the early years, approach the heat transfer concepts and phenomena in an unstable, limited, and isolated way. They associate the temperature of the objects with their size and attribute the thermal properties to the materials from which the objects are made. In relation to issues around the water state changes, young children seem to believe that steam is created by boiling water, but steam does not become water again as it disappears, or it is absorbed by solid objects. In addition, it appears that children's responses are satisfactory only when the change of state discussed is for phenomena that occur daily, such as for example ice cubes in liquids, and are not generalised for other materials.

The above literature informed this paper and provided a basis on which the current study was developed. The study presented here focused on children aged between 5 and 6 years old and aimed to explore these children's ability to construct a precursor model to support learning about the water change of state phenomenon. At the core of this precursor model lie two key concepts; the first concept relates to the ability to recognise the changes occurring in the physical state of a material, meaning the transitions from solid to liquid and from liquid to gas and vice versa. The second concept relates to the ability to recognise that heating or cooling is the sole cause for these changes to occur, focusing on heat transfer. The development of a precursor model, that will achieve a stable connection between the concept of state changes and the concept of thermal changes, can allow young children to describe the physical states of water and predict the evolution of the changes. In this study, the main research question focuses on whether, through systematically designed teaching activities, children aged between 5 and 6 years old are able to move from an intuitive approach to water state changes to the mental construction of a precursor model.

\section{Methodology}

The study involves a qualitative methodological approach, since it seeks to describe and understand in depth a phenomenon of interest in a context-specific setting (Patton 2002). It is important to bear in mind that due to the qualitative 
nature of the research involving a small sample, generalising results is prohibited. However, the paper allows to establish comparisons with other studies of a similar nature, contributing to the knowledge of young children's explanations of natural phenomena.

\section{Sample}

The sample included 91 children ( 43 boys and 48 girls) with an average age of 5 years and 2 months (S.D. 2 months), from nine classes of seven public kindergartens in Greece. The children were randomly sampled from those willing to participate in each class and with their parents' consent. The children that took part in the research had not previously attended any organised teaching activity on the changes of matter or the changes of state of water.

\section{Design}

The research design consisted of an individual teaching intervention which included eight stages, during which the children were asked to predict and explain the different phenomenon under investigation. At each one of these stages, children were asked to predict the development of a simple phenomenon in which the occurring change related to either heating or cooling, while carrying out a simple experimental process. During this process, the researchers discuss with the children, guiding them and trying to lead them to centrations (i.e. to focus on one salient aspect of the phenomenon and neglect others) in relation to the relationship between heating, cooling and the change of the water states. At each stage, the discussion ends when the researchers are certain that the communication between themselves and the child has nothing more to offer to the child (without giving the answer to the child).

Table 1 provides a summary of the stages while a more detailed description of each stage is also given below. At stage one, children are presented with a few ice cubes that are just taken out of the freezer (in the school's kitchen). The children are asked to predict what will happen to the ice cubes if they were heated. At the stage two, the ice cubes are heated using a camping gas fire (or similar) until they melt. When fusion is completed, the children are asked to describe the phenomenon (what happened) and compare the result to what they predicted a few minutes ago (during stage one).

Subsequently, at stage three, the children are encouraged to predict what will happen if part of the water (that is now in front of them, as a result of the melted ice

Table 1 Stages of teaching intervention

\begin{tabular}{|c|c|c|c|}
\hline & Summary & Materials & $\begin{array}{l}\text { Approxi- } \\
\text { mate length } \\
\text { of stage }\end{array}$ \\
\hline Stage 1 prediction & $\begin{array}{l}\text { Children are presented with some ice cubes } \\
\text { Children are asked to predict what will happen } \\
\text { to the ice cubes if they are heated }\end{array}$ & $\begin{array}{l}\text { Ice cubes } \\
\text { Heating source e.g. candle or camping gas fire }\end{array}$ & $5 \mathrm{~min}$ \\
\hline Stage 2 fusion experiment & $\begin{array}{l}\text { Ice cubes are heated until they melt } \\
\text { Children are asked to observe the phenomenon } \\
\text { and compare their observation to their predic- } \\
\text { tion }\end{array}$ & & $10 \min$ \\
\hline Stage 3 prediction & $\begin{array}{l}\text { Children are asked to predict what will happen } \\
\text { the water (that is now in front of them) is } \\
\text { heated again }\end{array}$ & $\begin{array}{l}\text { Water (from previous stage) } \\
\text { Heating source e.g. candle or camping gas fire }\end{array}$ & $5 \mathrm{~min}$ \\
\hline Stage 4 ventilation experiment & $\begin{array}{l}\text { The water is heated, and children are asked to } \\
\text { compare their observations to their prediction }\end{array}$ & & $10 \min$ \\
\hline Stage 5 prediction & $\begin{array}{l}\text { Children are asked to predict what will happen } \\
\text { when the rest of the water is heated while a } \\
\text { cold plate is being held over it }\end{array}$ & $\begin{array}{l}\text { Water (from previous stage) } \\
\text { Cold plate } \\
\text { Heating source e.g. candle or camping gas fire }\end{array}$ & $5 \mathrm{~min}$ \\
\hline Stage 6 condensation experiment & $\begin{array}{l}\text { The water is heated while holding a cold plate } \\
\text { on top of it } \\
\text { Children are asked to compare their observa- } \\
\text { tions to their prediction }\end{array}$ & & $10 \min$ \\
\hline Stage 7 prediction & $\begin{array}{l}\text { Children are asked to predict what will happen } \\
\text { if the water is placed into the freezer }\end{array}$ & $\begin{array}{l}\text { Water (from previous stage) } \\
\text { Freezer e.g. in school's kitchen }\end{array}$ & $5 \mathrm{~min}$ \\
\hline Stage 8 freezing experiment & $\begin{array}{l}\text { Children put the water in the freezer and occa- } \\
\text { sionally go back to check any changes until } \\
\text { the water becomes ice again } \\
\text { Children are asked to compare the result to their } \\
\text { prediction }\end{array}$ & & $\begin{array}{l}5 \text { min } \\
\text { and can } \\
\text { extend } \\
\text { into play } \\
\text { time }\end{array}$ \\
\hline
\end{tabular}


cubes) is heated and, in stage four, the water is heated using a camping gas fire (or similar). During stage four, the children observe the phenomenon of ventilation and compare the results to what they predicted before. In stage five children are asked to predict what will happen when the rest of the water is heated while a cold plate is being held over it. In stage six, the children observe the phenomenon of condensation during which water vapour condenses and is collected as a small amount of water. At the end of stage six children are asked to compare the results of their observations to what they had initially predicted while they are also encouraged to explain their answers.

Finally, in stage seven, the children are asked to express their prediction of what will happen if the water is placed back into the freezer. This was the same water that was collected during the previous stage of condensation. In stage eight, the children put the water in the freezer and occasionally go back to check any changes until the water becomes ice again. Stages one up to seven last for approximately $55 \mathrm{~min}$, while stage 8 might take longer and can extend during play time, as children will be going back to the freezer occasionally to check the water. The whole intervention is completed with the children comparing and explaining the results of the last stage to their initial prediction.

\section{Analysis and Findings}

During the above process, children's responses to the questions posed at each stage of the intervention were recorded. Children's responses were then transferred into SPSS under three categories: sufficient, intermediate and insufficient. The following criteria of evaluation were applied when analysing children's responses:

Sufficient responses were those provided by children who predicted and explained changes, associating them with thermic fluctuations on a qualitative scale, that is to say, in the way these changes can be appreciated by children of this age.

Intermediate responses were those provided by children who made correct predictions referring to a kind of change, without being associated with thermal phenomena, or the opposite.

Insufficient responses were those provided by children who failed to offer correct predictions and, when the children were asked to give explanations after the experimental activities, they did not express concrete ideas.

The inter-rater reliability of children's responses was calculated at $87 \%$ (Cohen's kappa coefficient at 0.87 ). To facilitate the organisation of this section, the results are presented in eight stages, based on the eight respective stages of the intervention (see design), while referring to the criteria of evaluation mentioned above.

\section{First Stage: Children's Predictions of What Will Happen to the Ice Cubes if Heated}

In the first stage, the ice cubes were placed in a metal tray and the children were asked to predict what would happen if the ice cubes were heated (using camping gas flame). Therefore, it becomes possible to determine whether children approach fusion as a thermal effect phenomenon or if they understand it as a property of ice. Children's representations were ranked in the following categories:

(a) Sufficient This category included the responses from 12 children who predicted that the ice will melt due to the heat created from the camping-gas fire. For example, 'they melt... because of the heat from the fire...' (child71).

(b) Intermediate This category includes 65 children's responses which recognise that the ice will melt, referring to everyday events and explanation, but without claiming a thermal effect factor. For example, 'they melt... the ice cubes melt... I know this because that is what happens with the ice cubes when I drink juice' (child-1).

(c) Insufficient The third category includes the answers of 14 children who do not refer at all to the ice melting or the phenomenon of fusion. As a result, this category would include responses from children that did not give an answer or replied with saying 'I don't know'. It would also include responses such as 'They will heat up.' (child-4), 'They will feel hot.' (child-39), 'They will burn.' (child-72), 'They will become very hot from the heat and we won't be able to touch them.' (child29).

\section{Second Stage: Children's Explanation of the Melting Ice Cubes}

For this stage, the ice cubes were placed over the camping gas flame and very quickly started melting until they completely liquefied. The participating children observed the process and were then requested to explain what happened. When analysing the responses that the children provided during this stage, the following representations were identified:

(a) Sufficient This category includes responses from 64 children relating liquefaction to the heat created from the camping gas fire, explaining that the ice cubes melted because of the heat from the flame. For example, 'The ice cubes became water... because we heated 
them.... To clarify the children's response the researchers asked: 'What if we didn't heat them and we only got them outside the freezer and just left it on the table?'. In this category the children's responses to this question would include examples such as 'they would still melt because they would be left outside... outside the freezer is hotter than inside the freezer...' (child-35).

(b) Intermediate 17 children recognise and report that the ice is melting but do not associate this change with heating it at the camping gas flame. Responses included in this category are similar to 'The ice melted...because we put them to melt' (child-46). To clarify the children's responses the researchers asked follow-up questions such as 'Where did we put them? Why did they melt?' Children's ideas in response to this, included answers such as 'We put them in the plate/saucer...' (child-51) or 'We put them up there.... (showing the camping gas) and that's why they melted.' (child-11), 'Because we left it the (showing the camping gas) for a while, and they melted...' (child-83). The children's responses included in this category do not indicate an appreciation of the link between heat and the liquefaction.

(c) Insufficient This category includes ten children's responses which did not provide an answer in relation to liquefaction. For example, 'I don't know...' (child17), 'I don't know what happened...' (child-10).

\section{Third Stage: Children's Predictions of What Will Happen if we Heat the Water}

During this stage, children were asked to predict what would happen if the camping gas fire was used to heat up the water resulting from the ice cubes. Children's representations were ranked in the following categories:

(a) Sufficient A small group of 22 children predicted that the water would evaporate. For example, when the researchers asked, 'What will happen if we heat the water for a long time?' and the children said, 'We will see smoke.' (child-6) or 'It will become smoke...' (child-49). To clarify the children's responses the researchers asked follow-up questions such as 'Why will we see smoke?', 'How will the smoke be created?'. In this category, children provided responses such as 'From the heated water...like it happens when boiling the kettle...' (child-62). The researchers would then ask questions such as, 'What will happen if we keep heating the water' and the children provide responses such as 'It will run out, it will leave with the smoke. We will need to put more water.' (child-82).

(b) Intermediate In this case, 53 children recognised that the water will be boiling hot, but they did not refer to the changes happening to the states of the water. For example, when the researchers asked: 'What will happen if I heat the water for a long time?' the children provided responses such as 'the water will boil... it will burn...' (child-31). To clarify the children's responses, the researchers would ask some follow-up questions such as 'What do you mean when you say it will burn?' and the children provided answers such as 'If you touch it you will burn' (child-60) or 'You will not be able to touch it. The water will be too hot...' (child-44).

(c) Insufficient Here, we had 16 children's responses which did not relate to heating the water or to the phenomenon of evaporation. For example, when the researchers asked questions such as 'What will happen to the water from the ice cubes if we heat it up for a long time?' Typical examples of children's responses in this category included 'It will catch fire.' (child-10) or 'I don't know...' (child-69).

\section{Fourth Stage: Children's Explanation of the Water Evaporation}

After the completion of the discussions generated during phase three, a small amount of water is placed in a transparent container and above the camping gas flame. During this phase, the children observe the water evaporating and a new discussion takes place which specifically focuses children's attention to the movement of the bubbles within the water. The children observe the bubbles, emerging at the bottom of the container and moving upwards towards the surface of the water, as well as the steam created at the surface of the water and moving upwards. For this stage, children's representations were grouped in the following categories:

(a) Sufficient After observing and discussing the phenomenon, 68 children related heating with evaporation. Typical responses in this category include examples such as 'The water was filled with bubbles and then became vapour...' (child-44) and 'All the water became smoke... water heated up and became smoke' (child-75). However, some children provided responses such as 'The water was heated by the fire and became vapour...' (child-55). In cases like this, the researchers would use questioning to unravel children's understanding. If the children provided responses that demonstrated that they used the word 'smoke' to refer to 'vapour', the researchers considered this to be a lack in vocabulary, rather than a lack of understanding necessarily, and noted the children's responses as 'efficient'. At this stage, it was also evident that some of the children that were previously not able to predict correctly (i.e. during previous stages) were now providing responses that were considered to be 'sufficient'. 
(b) Intermediate A total of 15 children recognised that the water was being heated by the camping gas flame and that steam was produced, but there was no reference to the change of the water state. The children in this group provided responses similar to 'We heated the water... and then we got smoke...' (child-90). As mentioned above, in cases like this, the researchers would use questioning to unpack children's understanding. This category includes those responses that were clearly indicating a lack of understanding, rather than a lack in vocabulary. The following conversation is a typical example of the dialogue that would develop between the researchers and a child whose responses would be noted as 'intermediate'. Researchers: 'Can you explain what happened?', Child: 'There is smoke...' Researchers: 'How was the smoke created?', Child: 'From the fire'. Researchers: 'And what about the water?', Child: 'The water was heated... and then we got smoke...'. Researchers: 'So, the smoke came from the water that was heated?', Child: '...from the heat, the smoke came from the heat...'. Researchers: And what happened to the water?'. Child: 'It became... very hot...'. As you can see from the example, in cases like these, the children's responses would indicate an 'intermediate' level of understanding.

(c) Insufficient In this category we have eight responses from children that refer to various aspects of the situation, such as the heating flame and the bubbles created, but without approaching any of the basic characteristics of the evaporation phenomenon. The following would be a typical example: Researchers: 'Can you explain what happened.', Child: 'The water is burning... the fire...'. Researchers: 'And what happened then?', Child: 'Then we had smoke and it went to the bubbles.'. Researchers: 'Where did the smoke go?', Child: 'To the bubbles.'. Researchers: 'And what happened to the water?', Child: 'Nothing...'

\section{Fifth Stage: Children's Predictions the Liquefaction of Vapor}

In this stage, children are asked to predict what will happen if the same procedure is repeated but this time placing a cold plate on the top of the boiling water. Children's responses, when answering this question, were grouped in the following categories:

(a) Sufficient Only one child's response referred to the liquefaction phenomenon as a thermal phenomenon, using a domestic experience to explain the prediction. More specifically, the child said 'If we put a plate there the smoke will fall onto it. Like on a pot... We will get water... on the plate...' (child-24). The research- ers then asked, 'How will this happen?' and the child explained 'From the some that will fall on the cold plate... like it happens on a pot's lid...' (child-24).

(b) Intermediate In this category we had 51 responses which recognised that a thermal phenomenon would take place but without predicting liquefaction as part of it. In this group we also have the responses of two children who did refer to liquefaction but not as a thermal phenomenon. Instead, they only related their response to their previous experiences, saying things such as 'The smoke will not be able to pass... but it will come out... from the sides...' (child-16). The researchers would follow-up with questions such as, 'Will we notice anything on the plate?' and the responses in this category would be similar to the following one: 'The plate will become warm... from the smoke... because it is hot from the fire...' (child-60).

(c) Insufficient In this category we have 39 answers in which children hardly refer to the phenomenon of liquefaction. For example, children's responses were similar to 'We will see smoke...' (child-17). When the researchers asked if there would be anything noticed on the plate the children ranked in this category replied negatively providing responses, with or without justification, such as 'No...' (child-4) or 'No because smoke is white...' (child-14).

\section{Sixth Stage: Children's Explanation of the Vapor Liquefaction}

After completing the discussions as part of stage five, the children observe the rest of the water being heated while the researchers hold a cold plate on the top of the water and in the course of the vapour (but not too close to the plate). During this phase, the conversation focuses on the change of the state of the vapour and the role of the cold plate in this. Then, the children are asked to explain the changes happening to the state of the vapour. Children's representations, as a result of this discussion, were grouped in the following categories:

(a) Sufficient A total of 75 responses were ranked as 'sufficient', when there was evidence that children understood the change in the vapour's state as a thermal phenomenon, with or without relating their explanation to previous/domestic experiences. For example, when the researchers asked, 'What happed to the plate?' the children in this group would provide responses similar to the following one: 'The smoke fell on the plate and it became water...' (child-26). Like in stage four, in cases like this, the researchers would ask further questions to ensure that if the children used the work 'smoke' to refer to 'vapour', because of a lack in vocabulary, 
rather than a lack of understanding. When the children were asked to explain their responses, the answers would be similar to the following one: 'Because it (the water) became cold when it fell on the cold plate... like before... that the water became smoke... now the smoke became water... it became cold...' (child-56).

(b) Intermediate In this category, we had 11 responses which did not recognise liquefaction as a thermal phenomenon. For example, the children said 'There is water... I can see water... on the plate...'. With the researchers following up to clarify how they think this happened, the children in this group provided responses such as: 'From the smoke... the smoke fell on the plate with force and it couldn't get away. He fell with force onto the plate and could not go through...' (child-88).

(c) Insufficient In this category, a total of 5 responses were classified as 'insufficient' since there was no reference made to the liquefaction phenomenon. For instance, responses in this group were similar to: 'It's smoke...' (child-10), 'I can see smoke... like before' (child-64). When the researchers followed-up with clarifying questions, the children in this category provided responses such as 'I don't know...' (child-17) or did not provide an answer at all (child-39).

\section{Seventh Stage: Children's Predictions of the Solidification of Water}

During the liquefaction phenomenon, the researchers collected a small amount of water. In the seventh stage, the children are asked to predict what will happen if that same water is placed in the freezer. Like before, the answers were classified into three categories.

(a) Sufficient This category included 80 responses that relate to the solidification phenomenon, recognising it as a thermal phenomenon. Specifically, responses were ranked as efficient when the children predicted that the water would 'Become ice...because we will make it cold... if we put it in the freezer it will become ice... because it's very cold in the freezer...' (child-47).

(b) Intermediate On the other hand, seven responses predicted solidification but without any reference to the thermal phenomenon, or the link remained at the level of the everyday experiences when the children tried to explain the phenomenon. In this case, children's responses were similar to: 'It will freeze... the water will become ice... that's what happen when we put water in the freezer... we put it like water and we get it out sometime like ice...' (child-9).

(c) Insufficient In this category, we have four children's responses which do not refer to the solidification phenomenon at all. All children in this case did not provide an answer at all or replied with 'I don't know...' (child90).

\section{Eighth Stage: Children's Explanations of the Solidification of Water}

At this last stage, the children and the researchers put the water in the freezer. The researchers then allow for a few minutes to go by. They then ask the children to return to the freezer to observe what happened to the water. The researchers then ask the children to provide an explanation. During this stage, children's responses were ranked as follows:

(a) Sufficient In this category, we had 82 responses from children that recognised the solidification phenomenon as a thermal phenomenon. The children's responses provided explanations that demonstrate their understanding of the thermal phenomenon such as: 'It became ice... from the cold in the freezer... many things, if we put them in the freezer they will become like ice...like juice and milk...because it's very cold in the freezer...' (child-62).

(b) Intermediate In this category, we had seven responses within which the role of the freezer was not clearly linked to the water becoming ice, since the main element in these responses was based on children's everyday experiences. For example, 'The water became ice... because we put it in the freezer'. When the researchers followed-up with clarifying questions the children responded with answers such as 'Because that's what happens when we put water in the freezer...' (child43) demonstrating that the children did not associated the freezer with cold and its association to the thermal phenomenon.

(c) Insufficient In this category, we had two responses from children that did not refer to the change of the state of water at all, nor to the fact that the water became ice. More specifically, in this category children did not provide an answer at all, or did not recognise that the water became ice, even when seeing the ice in the tray, or replied by saying 'I don't know...' (child-59).

\section{The Course of Children's Reasoning}

At the eight stages of intervention, the qualitative results that derived from the discussions with the children were presented and studied. It would be more beneficial though to explore the thinking process that the children followed during the whole discussion, in order to identify which children are closer to constructing a precursor model. Table 2 presents the frequency of children's responses at each stage of the process, the exact sequence of responses that each 


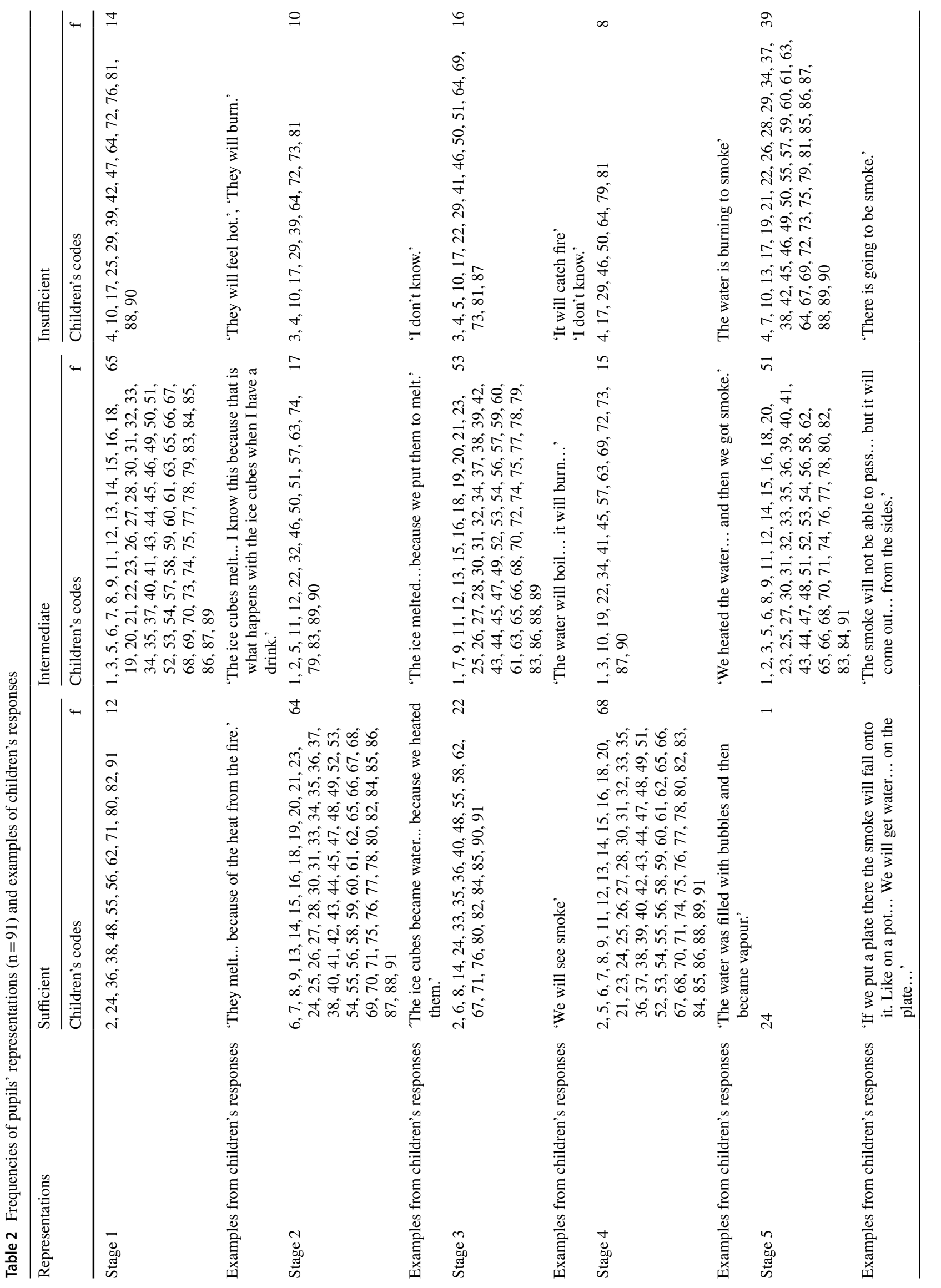




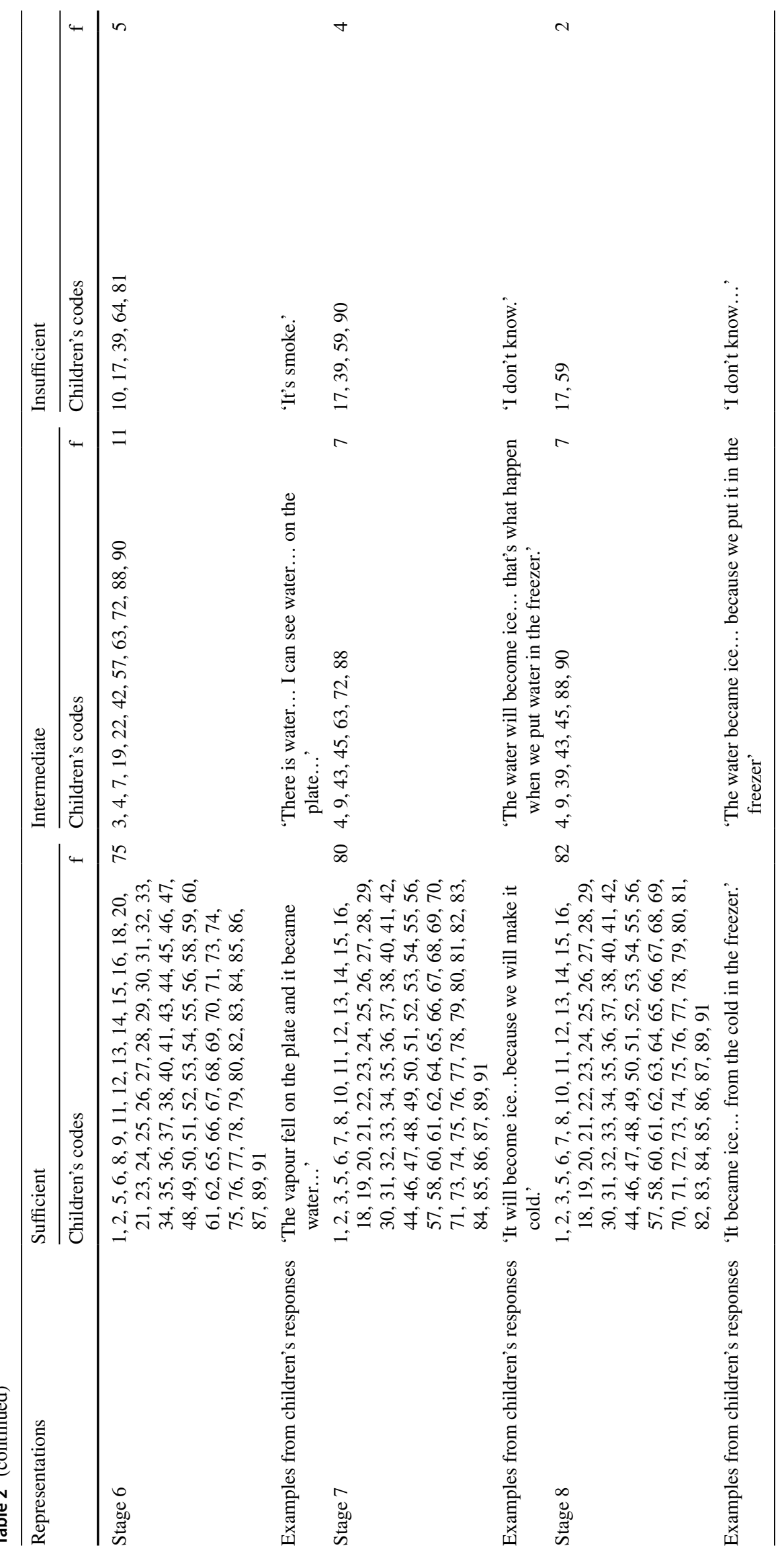


child provided during the teaching intervention as well as some examples of children's responses (numbering children from 1 to 91).

The Pearson's chi-squared test ( $\chi^{2}$ test) that was conducted in relation to the three categories (sufficient, intermediate, insufficient) at each stage, showed that the differentiation made between the three categories is statistically significant $\left(\chi^{2}=12.31, \mathrm{p}<0.004\right)$. It is apparent that all eight stages of the intervention process led to having more children with either sufficient of intermediate mental representations. In addition, the two-step cluster analysis indicated four categories of cognitive performances that the children have, which generally remain the same when moving between the different intervention stages.

- In the first category, there were 21 children that were generally unstable with their responses and most importantly did not attribute the change of state to a thermal change in the environment. These children consistently provided insufficient or intermediate mental representations, from stage 1 until stage 8 of the intervention process.

- In the second category, there were 12 children who provided mainly intermediate responses. Despite the fact that the children provided more sufficient mental representations at the last two stages, the overall picture indicates that these children had difficulties in relation to constructing stable mental representations.

- In the third category, there are 49 children whose responses after the second stage were stabilised and remained stable until the final stage, always expressing sufficient mental representations. The only exception, for all the children in this category, is the fifth stage of intervention, which seems that it did not allow the activation of an appropriate precursor model to support their reasoning. This category includes those children that seem to be able to construct a precursor model, which they apply consistently at the different stages.

- In the fourth category, there were nine children who were consistently able to provide a sufficient response from the beginning (stage 1), indicating the existence of a precursor model which consistently supported their reasoning. This precursor model pre-existed before the children entered the experimental process presented here, meaning that the construction of the precursor model cannot be attributed to the teaching intervention.

It is worth mentioning that the overall data analysis indicates that the 49 children (who were part of the third category) tended to provide more and more stable explanations as the intervention process was advancing. These explanations were based on the conceptual understanding that the water changes in state are linked to thermal changes in the environment, something which was evident not only during the prediction stages, but also during the explanation stages. It is also worth noting that, concerning gender, there were not any statistically significant differences between boys and girls.

\section{Discussion}

The study's findings indicate that it is possible, for children aged between 5 and 6 ears old, to consistently approach a complete sequence of water state changes, as part of a specifically designed teaching intervention. It appears that approximately $50 \%$ of the children that participated in the study, were able to successfully construct a stable conceptual framework which supported their understanding of the changes of water states, as a result of participating in this specifically designing teaching intervention. The rest of the children, either did not need the intervention (children in the fourth category) or the intervention did not support their understanding. Nevertheless, given that this conceptual framework is compatible with the curriculum, it can be suggested that a precursor model has been built and operated in the minds of these children, offering the potential for adequate descriptions and predictions. As shown in Table 1, during the last three stages, eight to nine out of ten children provided sufficient responses. This confirms the results derived from other studies, which focused on parts of the water state changes phenomenon (Tytler 2000) or focused on other thermal phenomena such as thermal expansion (Ravanis et al. 2013).

Nevertheless, the children in the first two categories, which are slightly more than a third of the sample, have a general instability in their responses, even for phenomena known to them from everyday life. This weakness is mostly noted when this group of children are asked to make predictions and less noted during their explanations, possibly because as the latter follow the interaction between the researchers and children (during each stage), suggesting that at the level of perception there is a possible influence on the child's reasoning. However, this influence does not appear to then transform into a more stable conceptual framework.

In addition, it is apparent that the fifth stage of the intervention process did not support the development of the children's understanding, as it did not help the children to attribute characteristics of the thermal phenomenon to the interaction between the vapour and the plate. The interviews revealed that most children did not recognise that the plate is acting as a 'cold' object in relation to the vapour. Although the children realised that there is liquification at the sixth stage, eight out of ten children searched for the thermal differences and used them to explain the change in the state of the water. 
When wondering about the cognitive transformation that occurs in children's thinking, it seems that the design, which allowed children's thinking to focus on successive status changes with successive predictions and experimental testing of forecasts, progressively led both to improved forecasting as well as improved explanations. From a cognitive point of view, it is particularly interesting that in this process, children aged five to six, seem to integrate in their thinking a series of more or less known changes from the daily routine, as they face them as phenomena due to thermal changes. Indeed, the literature review has shown that, while there is some empirical research that attempted to unpick how children of this age can understand isolated phenomena such as evaporation or condensation (Bar and Galili 1994), there is no research study that cover a complete sequence of changes which allows a step-by-step teaching process of a complete cycle, one that starts and ends on ice. Of course, the approach of these changes is done in a qualitative or semi-quantitative way on a 'warmer-colder' scale. But, as research has shown, for this age group, thinking on such a scale is a key element of a precursor model (Ravanis et al. 2013).

\section{Conclusion}

In this paper, we intended to present and discuss the results of a study that aimed to identify if, through participating in systematically designed teaching activities, children aged between 5 and 6 years old would be able to move from an intuitive approach to water state changes to the mental construction of a precursor model. The study was based on a teaching intervention that focused on supporting children's scientific learning through a series of specifically designed activities which aimed to activate a precursor model that would support the understanding of water state changes. The main aim of the proposed intervention is to support the learning that children already acquire mainly through play, but also through other forms of learning in the early years, and to offer a framework within which early years teachers can potentially support children construct their knowledge and possibly overcome misconceptions.

As mentioned before, the concept of the precursor model in this paper refers to cognitive entities whose fundamental elements are compatible with those of the scientific models used in the processes of learning and teaching science (Lemeignan and Weil-Barais 1993, 1994; Weil-Barais 2001). Precursor models include only a certain number of the characteristics that mental representations have, and therefore their range and applicability is inevitably limited. In terms of knowledge construction, precursor models function in the minds of children as intermediaries between mental representations of reality and scientific knowledge and prepare children's thinking by forming the basis for a cognitive path towards cognitive processing and the formation of more complex models. The findings suggest that the precursor model, which children construct as part of this study, allows them to describe, predict and explain the changes of the state of water, in a way that is in accordance with the scientifically accepted explanation as well as the model used when teaching science in formal educational settings. Thus, the children's responses are either sufficient or intermediate, as the process and the phenomenon investigated evolve.

It worth noting that the study presented here is part of a more general trend, the main aim of which is to explore and understand the ability of young children to approach phenomena of natural sciences, in order to develop activities which will then be integrated into curricula and teaching practices. Often, these studies are part of the Piagetian and Vygotskian, socio-cognitive or socio-cultural frameworks, while, from a methodological point of view, they focus on the analysis of interactions between children and teachers or on pre- and post-replies of children in specially designed experimental situations. In this case, the aim was to systematically detect and address the successive reflections formulated by the children about the relationship of phenomena to the factors of heating and cooling, by following the successive stages of the activity. To achieve this, children's predictions and explanations were recorded, both before and after each phenomenon of change of status, as well as children's way of thinking when they predict, monitor the evolution of the phenomena, confirm or contradict their prediction and interpret successively the changes that are happening. It is therefore apparent that this approach, of successive predictions and tests, in combination with having only one variable in every change of condition (heating/cooling), allows young children to develop a precursor model, i.e. a mental construction in which the basic elements are compatible with scientifically accepted knowledge.

The study seems to confirm that such an approach contributes to the construction of a precursor model in preschoolers' thinking. At the methodological level, this succession of experimental situations, during which we ask for predictions and explanations in relation to the changes in the state of water, leads the children's thinking to a focus on the only factor that intervenes: the thermal environment that is recognised by children with a qualitative scale 'warmer-colder' (Ravanis et al. 2013). In this way, it is possible to unidirectionally connect the state of the water with the heating or cooling of the material. From this perspective, the development of a precursor model seems to be able support children's learning of science and the proposed intervention can support children's knowledge construction.

It is worth noting that the success of the intervention can be even higher if children are allowed to further explore these ideas during play. It is proposed that early 
years teachers could adopt and use this intervention for different science topics within the early years curriculum, as an additional tool to support children's scientific learning. Such interventions should be used to build upon the learning that children acquire through play. Furthermore, such interventions should be used in moderation as they can be time-consuming, both in their design and their delivery, and should not replace children's learning through play (Sylva et al. 2004; Samuelsson and Carlsson 2006, 2008).

It is necessary to carry out further studies to see if this precursor model can be generalised to other materials or if it is limited to water. This primary form of thermal phenomena provides an appropriate framework to explore and approach scientific phenomena. However, the most important issue is to create conditions for these phenomena to be approached and explored within real early childhood education contexts of teaching, as well as when developing curriculums and practice.

Open Access This article is distributed under the terms of the Creative Commons Attribution 4.0 International License (http://creativeco mmons.org/licenses/by/4.0/), which permits unrestricted use, distribution, and reproduction in any medium, provided you give appropriate credit to the original author(s) and the source, provide a link to the Creative Commons license, and indicate if changes were made.

\section{References}

Allen, M., \& Kambouri-Danos, M. (2016). Substantive conceptual development in preschool science: Contemporary issues and future directions. Early Child Development and Care, 187(2), 181-191.

Ampartzaki, M., \& Kalogiannakis, M. (2016). Astronomy in early childhood education: A concept-based approach. Early Childhood Education Journal, 44(2), 169-179.

Bar, V. (1989). Children's views about the water cycle. Science Education, 73(4), 481-500.

Bar, V., \& Galili, I. (1994). Stages of children's views about evaporation. International Journal of Science Education, 16(2), 157-174.

Bradley, L. S. (1996). Children learning science. Oxford: Nash Pollack.

Canedo-Ibarra, S. P., Castelló-Escandell, J., García-Wehrle, P., \& Morales-Blake, A. R. (2010). Precursor models construction at preschool education: An approach to improve scientific education in the classroom. Review of Science, Mathematics and ICT Education, 4(1), 41-76.

Chen, I. (2007). An electronic textbook on instructional technology. University of Colorado at Denver School of Education. Retrieved February 24, 2010 from http://viking.coe.uh.edu/ ichen/ebook/ et-it/cover.htm.

Clement, J., Brown, D. E., \& Zietsman, A. (1989). Not all preconceptions are misconceptions: Finding 'anchoring conceptions' for grounding instruction on students' intuitions. International Journal of Science Education, 11(5), 554-565.

Cruz-Guzmán, M., García-Carmona, A., \& Criado, A. M. (2017). Aprendiendo sobre los cambios de estado en educación infantil mediante secuencias de pregunta-predicción comprobación experimental [Learning about state changes in early childhood education through question-prediction sequences experimental testing]. Enseñanza de las Ciencias, 35(3), 175-193.
De Vries, R. (2000). Vygotsky, Piaget, and education: A reciprocal assimilation of theories and educational practices. New Ideas in Psychology, 18, 187-213.

Delserieys, A., Jegou, C., Boilevin, J.-M., \& Ravanis, K. (2018). Precursor model and preschool science learning about shadows formation. Research in Science and Technological Education, 36(2), 147-164.

Driver, R., Squires, A., Rushworth, P., \& Wood- Robinson, V. (2001). Making sense of secondary science-Research into children's ideas. New York: RoutledgeFalmer.

Ergazaki, M., Valanidou, E., Kasimati, M. C., \& Kalantzi, M. (2015). Introducing a precursor model of inheritance to young children. International Journal of Science Education, 37(18), 3118-3142.

Fleer, M. (1996). Early learning about light: Mapping preschool children's thinking about light before, during and after involvement in a two week teaching program. International Journal of Science Education, 18(7), 819-836.

Kambouri, M. (2011). Children's misconceptions and the teaching of early years science: A case study. Journal of Emergent Science, $2(2), 7-16$.

Kambouri, M. (2015). Investigating early years teachers' understanding and response to children's preconceptions. European Early Childhood Education Research Journal, 25(3), 907-927.

Kampeza, M. (2006). Preschool children's ideas about the Earth as a cosmic body and the day/night cycle. Journal of Science Education, 7(2), 119-122.

Kampeza, M., \& Ravanis, K. (2009). Transforming the representations of preschool-age children regarding geophysical entities and physical geography. Review of Science, Mathematics and ICT Education, 3(1), 141-158.

Küçüközer, H., \& Bostan, A. (2010). Ideas of kindergarten students on the day/night cycles, the seasons and the moon phases. Journal of Theory and Practice in Education, 6(2), 267-280.

Lemeignan, G., \& Weil-Barais, A. (1993). Construire des concepts en physique, build concepts in physics. Paris: Hachette.

Lemeignan, G., \& Weil-Barais, A. (1994). A developmental approach to cognitive change in mechanics. International Journal of Science Education, 16(1), 99-120.

Levins, L. (1992). Students' understanding of concepts related to evaporation. Research in Science Education, 22(1), 263-272.

Pantidos, P., Herakleioti, E., \& Chachlioutaki, M. E. (2017). Reanalysing children's responses on shadow formation: A comparative approach to bodily expressions and verbal discourse. International Journal of Science Education, 39(18), 2508-2527.

Patton, M. Q. (2002). Qualitative research and evaluation methods (3rd ed.). Thousand Oaks, CA: Sage Publications.

Ravanis, K. (2014). Les représentations des enfants de 5-6 ans sur la fusion et la solidification du sel, comme support pour le déploiement des activités didactiques [Representations of 5-6 years old children on the fusion and solidification of salt, as support for the deployment of the teaching activities]. International Journal of Research in Education Methodology, 6(3), 943-947.

Ravanis, K. (2017). Early childhood science education: State of the art and perspectives. Journal of Baltic Science Education, 16(3), 284-288.

Ravanis, K., \& Bagakis, G. (1998). Science education in kindergarten: Sociocognitive perspective. International Journal of Early Years Education, 6(3), 315-327.

Ravanis, K., Papandreou, M., Kampeza, M., \& Vellopoulou, A. (2013). Teaching activities for the construction of a precursor model in 5-6 years old children's thinking: The case of thermal expansion and contraction of metals. European Early Childhood Education Research Journal, 21(4), 514-526.

Samuelsson, I. P., \& Carlsson, M. A. (2008). The playing learning child: Towards a pedagogy of early childhood. Scandinavian Journal of Educational Research, 52(6), 623-641. 
Samuelsson, I. P., \& Johansson, E. (2006). Play and learning: Inseparable dimensions in preschool practice. Early Child Development and Care, 176(1), 47-65.

Russell, T., Harlen, W., \& Watt, D. (1989). Children's ideas about evaporation. International Journal of Science Education, 11(5), 566-576.

Sylva, K., Melhuish, E., Sammons, P., Siraj-Blatchford, I., \& Taggart, B. (2004). The effective provision of pre-school education (EPPE) project: final report. London: SureStart DfES Publications Ref $\mathrm{SSu} / \mathrm{FR} / 2004 / 01$.

Tytler, R. (2000). A comparison of year 1 and year 6 students' conceptions of evaporation and condensation: Dimensions of conceptual progression. International Journal of Science Education, 22(5), 447-467.

Weil-Barais, A. (2001). Constructivist approaches and the teaching of science. Prospects, 31(2), 187-196.

Publisher's Note Springer Nature remains neutral with regard to jurisdictional claims in published maps and institutional affiliations. 